\title{
La designación occidental en la categoría analítica del MENA y su influencia en la comprensión del continente africano
}

Beatriz Pineda Ríos*

\section{Resumen}

Zl objetivo general de este texto es analizar cómo la región "MeCdio Oriente y norte de África” es una categoría analítica cuya construcción histórica posee un componente relevante de designación y representación por parte de Occidente en los países que incluye, lo que influye directamente en la manera de comprenderlos, estudiarlos y analizarlos. Centrándonos en los países del norte de África, reflexionaremos cómo la categoría del MENA ha sido un elemento fundamental en la concepción de un África dividida: un África "blanca” y musulmana, frente a un África subsahariana, “negra” y cristiana. En este sentido, un objetivo específico es identificar los intereses políticos occidentales coloniales en África tras la designación de la región del MENA, expresados en el discurso orientalista.

\author{
Palabras clave \\ Norte de África, África subsahariana, Medio Oriente, \\ MENA, colonial(ismo).
}

Fecha de recepción:

marzo de 2021
Fecha de aceptación:

junio de 2021

\footnotetext{
"Licenciada en filosofía por la Universidad Veracruzana; cursa la maestría en Estudios Internacionales en la Facultad de Ciencias Políticas y Sociales de la Universidad Nacional Autónoma de México. Contacto: beapir@hotmail.com ORCID: https:/orcid.org/0000-0001-8127-4131
} 
54 LA DESIGNACIÓN OCCIDENTAL EN LA CATEgORÍA ANALítica DEL MENA Y SU INFLUENCIA EN La COMprensión del Continente africano / Beatriz Pineda Ríos

The Western Designation in the Analytical Category of MENA and its Influence on the Comprehension of the African Continent

Keywords

North Africa, Sub-Saharan Africa, Middle East, MENA, Colonial(ism).

\section{Abstract:}

The main objective of this paper is to analyze how the "Middle East and North Africa" regions are analytical categories, whose historical construction has a relevant component of designation and representation by Western countries' ideology that influences the way of understanding, studying, and analyzing them. Focusing on the North African countries, we will reflect on how the MENA category has been a fundamental element in the conception of a divided Africa: a white and Muslim Africa, compared to a black and Christian sub-Saharan Africa. In this sense, a specific objective is to identify the western colonial political interests in Africa after the designation of the MENA region, expressed in the orientalist discourse.

\section{Introducción}

La "región de Medio Oriente y norte de África" (MENA, por sus siglas en inglés), "designa tanto a una unidad geográfica y geopolítica que comparte una historia, una estructura social y una cultura en torno al islam" (Calduch, 2008, p. 5); así como a una "categoría analítica cuya construcción histórica posee un componente muy relevante de designación y representación por parte de Occidente en los territorios del norte de África y Oriente Medio" (Sestafe, 2019, p. 56), lo cual influye directamente en la manera de comprender, estudiar y analizar a los países que incluye.

A pesar de que, con el desarrollo de teorías posestructuralistas como la teoría decolonial, poscolonial o el constructivismo en la década de 1970, "el debate al respecto ha estado presente, no ha llegado a constituir una cuestión que destaque en las diversas Ciencias Políticas y Sociales" (Sestafe, 2019, p. 73). Contrario a ello, dos décadas más tarde, en 1990, el término MENA ya se 
encontraba visiblemente consolidado en las Relaciones Internacionales, los estudios de área, y las Ciencias Políticas, designando tanto a países árabes situados en el norte de África como al conjunto de países de Oriente Medio, y considerando esta región, como parte esencial de la "civilización islámica" por su importancia histórica y cultural (Taboada, 1997).

Es importante tener presente que los países en cuestión mantienen una posición geoestratégica sumamente relevante, en especial en el comercio petrolífero y de mercancías entre el mar Mediterráneo y el océano Índico a través del mar Rojo (Taboada, 1997). Por ello, también organizaciones internacionales como el Banco Mundial y organismos como la UNICEF, comenzaron a recurrir al término para referirse a la región que se extiende horizontalmente desde Marruecos hasta Irán.

Sin embargo, hasta ahora es imposible delimitar la extensión exacta de la región ${ }^{1}$ y su entendimiento depende de la organización, institución, entidad o individuo que lo emplee; se trata de una categoría analítica elástica (Sestafe, 2019) que pretende, pese a ello, conservar el mismo significado: "la denominación a un ente geográfico cuyos países comparten una serie de rasgos culturales suficientes para ser comprendidos como región" (Sestafe, 2019, p. 56).

Así surgirán preguntas como, ¿dónde comienza la región del MENA?, ¿en Afganistán?, ¿en Persia?, y ¿qué hay con incluir en el mismo término a los países del norte de África?

Al designar al norte del continente africano, a veces llamado África Blanca, se refiere a la parte más septentrional del continente e incluye a Argelia, Egipto, Libia, Marruecos, Túnez, Sudán, y el Sahara Occidental - aunque estos dos últimos no siempre se incluyen porque por lo general no se consideran países de Oriente Medio- bajo el argumento de tener mayor similitud lingüística, religiosa y cultural con los países de Medio Oriente, que con sus

El acrónimo es a veces análogo al término Great Middle East (Gran Oriente Medio), acuñado por la segunda administración Bush para referirse al área de Medio Oriente y también a otros países de mayoría musulmana como Irán, Turquía y Pakistán (De la Rosa, 2012). 
vecinos del África subsahariana. Asimismo, existen preguntas acerca de la categoría MENA, tales como, “¿qué rasgos culturales e históricos son aquellos que permiten incluir o excluir a determinados países en esta región construida desde occidente?”.

En este sentido, en consideración a la existencia de diferentes experiencias históricas e identidades culturales y nacionales dentro de la misma región, Laura Sestafe observa el hecho de que los países a los que hace referencia el MENA pertenecieron a un imperio determinado en algún momento de la historia (Sestafe, 2019), es decir, ¿Cuán relevante es esto para la construcción y definición del término (MENA)? Tanto el continente africano como el Medio oriente y algunas partes de Asia, han experimentado por largo tiempo el colonialismo y la explotación de sus recursos culturales, naturales y humanos por parte de los mismos países europeos. Sin embargo, una parte importante de la manifestación colonial que no debe dejarse de lado, son las construcciones epistemológicas y designaciones territoriales impuestas.

En muchas excolonias de África y pueblos del Medio Oriente, dichas construcciones y designaciones han logrado permear en los actores regionales a los que designa, modificando las dinámicas propias de autopercepción e identidad. "El arabismo como corriente ideológica surgida en la primera mitad del siglo $\mathrm{XX}$, el panarabismo durante la segunda mitad de este siglo" (Bilgin, 2019, pp. 57-58), los procesos de etnitización en gran parte de los países africanos, así como la categoría regional del MENA, son una buena muestra de ello. En este último caso, "la producción intelectual orientalista tiene un papel central respecto a la homogeneización cultural de las sociedades que se incluyen en estos territorios, asimilado posteriormente para designar un punto de gran importancia geoestratégica para Europa y Estados Unidos" (Sestafe, 2019, p. 59).

2 La pregunta de equé actores deciden sobre la conformación de la región?, ha sido formulada y discutida en diversos artículos de la disciplina de las Relaciones Internacionales, entre ellos: Bilgin, Pinar (2019), y Roughi, Ramzi (2012). 
Buscar una mejor compresión de las inquietudes planteadas, implica un acercamiento al desarrollo histórico del MENA como categoría regional y cultural, cuestión respecto de la cual Laura Sestafe, en su artículo antes mencionado, presenta aportaciones sintéticas relevantes que se retomarán más adelante.

Esta autora se remite a "la gran expansión del islam a través de los omeyas" para explicar parte de los elementos árabes e islámicos con el que asocia a la región del MENA. En la Edad Media, en los siglos VII y VIII, el califato árabe omeya tuvo gran importancia y se extendió desde el sur de España, toda la costa y parte del interior del norte de África. En este proceso de expansión la dimensión religiosa fue fundamental, por lo que se introdujo el islam en todos los territorios conquistados (Balci, 2018). Con el fin de consolidar el poder del califato y el factor religioso, también se llevaron a cabo políticas de arabización, cuestión que iba acompañada del árabe como lengua común a las sociedades que se encontraban desde la actual Marruecos, hasta la frontera persa (Sestafe, 2019).

Todo esto influiría profundamente en las culturas del norte de África y Oriente Medio, las cuales adoptaron elementos culturales árabes que conservaron, incluso tras la desintegración del califato, lo que puede verse en los imperios musulmanes almorávide y almohade en el sur de la península ibérica y todo el norte de África. Ambos imperios mantuvieron el árabe como idioma y el islam como religión (Fierro, 2010).

Esta primera expansión de la confluencia entre el islam y la cultura árabe siguió en desarrollo a lo largo del continente africano con las rutas y vínculos comerciales entre los imperios del norte de África y diferentes pueblos del Sahel, lo que incluye el norte de los actuales países de Mauritania, Malí, Níger, Chad y Sudán. Lo mismo sucedió en los intercambios comerciales de los pueblos árabes de la península arábiga, con aquellos del Cuerno de África. De la misma forma, al ser población musulmana del Sahel y el este de África mayoritariamente suní, en Sudán, Eritrea y Etiopía, las órdenes sufíes tienen una gran importancia (Levtzion \& Powels, 2000). Sin embargo, de acuerdo con Levtzion y 
Hopkins (2000), estos dos últimos países no se incluyen en la región del MENA.

Antes de proseguir con el texto, es pertinente abordar la diferencia entre los términos árabe y musulmán. Musulmanes son aquellas personas que creen y practican el islam, es decir, una religión monoteísta que se rige por las escrituras del Corán y que surgió en el siglo VII en Arabia de la mano de Mahoma (Tamayo, 2009). Por su parte, "los árabes, como grupo étnico y lingüístico, se caracterizan por su común empleo de la lengua árabe. Procedentes de la península arábiga, en el siglo VII y VIII habrían emigrado a diferentes territorios, extendiendo su influencia por las regiones del norte de África y Oriente Próximo" (El Orden Mundial, 2019). Así se expandió también su lengua y su religión mayoritaria, el islam.

Suelen considerarse veintidós los países de mayoría árabe (los mismos que componen la Liga Árabe). Sin embargo, no todos los árabes que habitan estos países son necesariamente musulmanes. Asimismo, tampoco en los países árabes la población es exclusivamente árabe, y existe también cierta variedad étnica: "en países como Marruecos o Argelia, los árabes conviven con otras etnias como la bereber" (Falsa, 2006, p. 159). Por último, "no todos los Estados de mayoría musulmana son árabes, e incluso en Oriente Próximo pueden encontrarse ejemplos como Irán y Turquía” (Falsa, 2006, p. 160).

Así, en la actualidad las palabras “árabe” y "musulmán” son distintas y hacen referencia a rasgos muy diferentes. De forma resumida, los árabes comparten el grupo sociocultural y lengua; mientras que los musulmanes, la religión.

Es importante mencionar que, aunque en países como Somalia, Malí o El Chad, el árabe se convertiría en idioma oficial (Al Rahim, 2008), el grueso demográfico de estos países no es árabe. Los grupos socioculturales que los componen preservan sus propias lenguas (Fierro, 2010). Respecto de las prácticas religiosas, la situación varía. A propósito de los mismos países antes señalados, "Malí se considera una sociedad islámica, con más del 90\% de la población practicando el Islam" (World Population Review, 
2021); Somalia es un país suní-musulmán, de acuerdo con los datos de World Factbook (2021) - que no han sido actualizados desde 2019- y en Chad, el 52.1\% de la población también es musulmana (World Factbook, 2021). Sin embargo, esta cuestión ha sido paulatina, ya que en un inicio "la entrada del islam en el Sahel y cuerno de África no supuso la conversión y adaptación mayoritaria del islam por parte de las comunidades que residían en la región, aunque sí se produjeron sincretismos culturales" (Insoll, 2003, p.36). Un ejemplo es lo que algunos autores llaman "islam africano" (Insoll, 2003, p. 37).

En los siglos siguientes y en las diversas regiones donde se asentó el islam, el término árabe se refería, sobre todo, a los beduinos, algunos de los cuales lo adoptaron como autodenominación. ${ }^{3}$ Por extensión, en África del Norte fue aplicado también al "habitante del campo" (Taboada, 1997, p. 89), mientras que, en África subsahariana, los árabes eran los musulmanes, independientemente de su color de piel (Lane, 1863).

En Europa también coexistieron varios usos del término en cuestión:

En los escritos españoles de los siglos XVI y XVII, los árabes son los nómadas beduinos de África del Norte, opuestos a los moros, habitantes de las ciudades; esto refleja obviamente el u so que hacían los mismos habitantes de África del Norte, que estaban en estrecho contacto con los españoles después de las invasiones de tribus árabes que sufrió su región en el siglo XVI (Taboada, 1997, p. 92).

Es posible entonces datar el inicio de la arabización de África del Norte en esta época.

Los sultanes del Imperio Otomano mantuvieron el título de califas desde el siglo XVI hasta 1918, con el fin de la Primera Guerra Mundial. Sin embargo, desde mediados del siglo XIX, tanto

3 Los beduinos pueden autodenominarse badu, o sea, beduino. Pero el término más común es árabe (Dickson, 1959). 
Francia como Reino Unido ya habían comenzado sus primeras incursiones en el norte de África:

El fin de la guerra otorgó a Gran Bretaña un lugar de preminencia en las regiones situadas entre Egipto y La India, y cuya defensa dependía de dos comandos militares: el NearEast y el MiddleEast Command. En 1932 las operaciones aéreas fueron unificadas bajo el MiddleEast Command. Durante la Segunda Guerra Mundial, la comandancia de los Ejércitos Aliados fue disputada por Francia e Inglaterra, que terminaron por dividirla entre sí, de manera que a Francia tocó la del Proche Orient y a Gran Bretaña la del Middle East. Con la caída de Francia, un comando del Middle East inglés se trasladó a El Cairo, desde donde controló las operaciones militares de una zona que pasó por ello a formar parte del Middle East (Taboada, 1997, p. 88).

Después de la guerra no se volvió a las denominaciones anteriores. Churchill argumentó que un millón de ingleses habían muerto por el Middle East en Egipto o Siria, por lo que estos países deberían seguir siendo parte del mismo. El uso de tales nombres regionales es una expresión clara del ejercicio del poder occidental por parte de las potencias mundiales de la época. Esto, además, es producto de una visión del mundo que empezó a fortalecerse desde el siglo XVIII, y que se refiere a Oriente como a todo aquello que no es Occidente, en palabras de Edward Said, un "Otro" frente a un "Nosotros" (Said, 2013).

En aquel siglo, la capacidad de dominación occidental sobre las sociedades orientales se justificaba en la superioridad de los primeros como civilización, lo que generaba, por un lado, una labor moral de mission civilisatrice (Wallerstein, 1999), que se expandía también sobre Asia y toda África y, por otro lado, legitimaba su capacidad de representar a las sociedades orientales, tanto asiáticas como africanas, supuestamente incapaces de hacerlo por sí mismas.

A principios del siglo XX, Francia estableció protectorados desde Marruecos hasta Túnez; Italia en Libia; y Reino Unido en 
Egipto, Yemen del Sur y los emiratos de Qatar y Kuwait, además de adentrarse en los territorios musulmanes del Sahel y África del este (Knut, 2010).

En este contexto comenzó a propagarse entre una clase media educada y la élite intelectual árabe, la idea de la existencia de una identidad propia árabe que diferenciaba a esta comunidad frente a los occidentales, los otomanos, los persas, la población racializada del Sahel y frente a otras minorías étnicas, como los kurdos o los bereberes (Choueiri, 2000).

En sus inicios, el arabismo como identidad se basaba en unos valores culturales y una historia compartida: una narración histórica, filosófica y espiritual que ponía mucho énfasis en el periodo de grandeza del califato omeya (Choueiri, 2000). Esto tuvo una fuerte influencia en el deseo de desarrollar una base teórica que sustentara la independencia de los pueblos árabes. Tal base fue el arabismo mismo como identidad, que refiere a la unión y solidaridad entre todos los pueblos árabes (Sestafe, 2019). Ello también constituyó la base del desarrollo teórico del panarabismo frente a los opresores otomanos y europeos.

Entre 1860 y 1870, aproximadamente tres décadas antes del surgimiento del panarabismo como movimiento ideológico, encontramos el surgimiento del panislamismo, movimiento que buscaba la unidad de la comunidad musulmana y su adscripción a una lectura ortodoxa del Corán y la sharía. Es importante recordar que tal movimiento "no se opuso al panarabismo ni viceversa: ambas fueron reacciones a la misma problemática de la opresión colonial y compartían una base antimperialista, anticolonial e incluso nacionalista, apelando a una identidad cultural específica y su unidad" (Sestafe, 2019, p. 62).

Mientras tanto, del lado de occidente y el desarrollo de la categoría del MENA, con el avance de investigaciones de procesos históricos diversos, fue imposible restringir la "civilización islámica" a Oriente Medio y el norte de África, por lo que el norte de Malí, Chad, Níger y Etiopía, así como todos los países comprendidos entre Irán, China y la India, fueron sumados. Sin embargo, es evidente que existen grandes diferencias culturales en todos estos 
territorios. Para dar coherencia a tal decisión, los orientalistas dieron una gran importancia al elemento árabe presente en el islam, echando mano de algunas ideas panarabistas y panislamistas, situando como su epicentro el mundo árabe y Oriente Medio.

En Europa esta cuestión dio gran impulso al desarrollo de la disciplina académica del orientalismo, la cual formula una perspectiva occidental que señala las prácticas que los orientales deben mantener y realizar (Sestafe, 2019), entre ellas, la importancia del mundo árabe y musulmán de Oriente Medio frente a las sociedades africanas musulmanas, estableciendo una línea divisoria entre el norte de África, del Cuerno de África y África Subsahariana, pese a que distintos procesos culturales y políticos se hayan expandido por todas estas regiones sin discontinuidades abruptas.

Es curioso observar que se llama orientalistas a quienes se dedican al estudio de las sociedades de Asia, Oriente y norte de África, sin circunscribirse a los estudios africanos en este último caso (Sestafe, 2019). Por su parte, los países del Cuerno de África se incluyen en el mundo árabe, dependiendo de la temática de estudio. Pronto, en el marco del orientalismo, se generaría un intenso debate en torno a la capacidad de las sociedades no occidentales de insertarse en la Modernidad y adaptarse a sistemas democráticos.

A pesar de que intelectuales provenientes de Oriente Medio y el norte de África como los marroquíes Abdallah Laroui y Mohammed Abed al-Jabri, y los egipcios Anwar Abdel-Malek y Samir Amin, entre otros, participaron activamente y realizaron importantes aportaciones a esta cuestión durante las décadas de 1960 y 1970, en Occidente los análisis se centrarían en la falta de estados musulmanes "modernos" y "democráticos”, destacando la presencia del islam en la estructura de los nuevos estados-nación del norte de África y Oriente Medio, y las dificultades para la modernización que esto suponía Egipto y Siria (Sestafe, 2019). "Así, el orientalismo influyó en el enfoque y concepción que se tenía de las sociedades del norte de África y Oriente Medio, y su representación" (Sestafe, 2019, p. 69).

El islam tiene una relación directa con la cultura árabe en tanto que surgió en la Península Arábiga, donde se encuentran los 
dos lugares más santos del islam; también El Corán, los hadith y la sharía están escritos en árabe, idioma en el que históricamente se ha estudiado también el derecho islámico. Sin embargo, siendo un proceso tan ampliamente extendido, en el caso de los pueblos del Sahel y del Cuerno de África, estos africanizaron el islam y se desvincularon en gran medida de la influencia árabe (Sestafe, 2019).

Esto guía el análisis en torno a que, aunque la gran mayoría de los países que se incluyen dentro del MENA son árabes, "coexisten en la región diferentes pueblos cuyas culturas son igualmente longevas y que se han preservado tras su conversión al islam, revirtiendo la arabización del islam a pesar de los rasgos culturales árabes de los que no es posible desvincular esta religión" (Sestafe, 2019, p. 64).

A partir de 1980 se produjo un cambio historiográfico y discursivo en torno al mundo árabe e islámico de Oriente Medio que comenzó, por un lado, en 1978 con la publicación de Edward W. Said -Orientalismo- y, por otro, con el resurgimiento de los movimientos y partidos políticos islamistas y la Revolución Islámica de 1979, cuyo discurso antimperialista, y en especial antiestadounidense y contra Israel, generó gran interés académico como alerta en Estados Unidos de Norte América (Sestafe, 2019).

En este contexto, en 1996 el estadounidense Samuel Huntington publicó "El choque de Civilizaciones y la reconfiguración del orden mundial", obra que tuvo consecuencias directas en el discurso sobre el islam. Huntington consideraba que la cultura no es fruto de un contexto histórico, político, económico o social determinado, sino que es algo inherente a los diferentes grupos humanos que conforman las grandes "civilizaciones". Situado en una perspectiva determinista, el autor rechazaba la multiculturalidad y consideraba imposible desprenderse del núcleo cultural al que cada individuo pertenece (Huntington, 2015).

En esta lógica, Huntington recuperó el concepto de "civilización islámica" y la dividió en "subcivilizaciones", entre ellas la árabe, la persa, la turca y la malaya, sin identificar aquellas musulmanas de África del Norte. Tampoco terminó por definir algo tal 
como una "civilización africana" (Huntington, 2015). Esta cuestión sin duda acentuó la concepción de un Medio oriente no africano, expresando también indiferencia respecto de África negra, sus pueblos, culturas y su participación en la historia del mundo.

Se planteaba al inicio del texto, que un proceso de categorización, designación y conceptualización como el caso del MENA, posee un profundo componente occidental que influye directamente en la manera en la que las propias regiones y países señalados se comprenden y analizan a sí mismos. El continente africano sin duda ha sido una región que se ha visto impactada por tales perspectivas occidentales. Una de ellas es la de un África dividida en dos: "por un lado, un norte de África, más cercano a occidente y las culturas del Medio Oriente, un África no negra (aunque tampoco blanca); y por otro, un África subsahariana, también llamada África negra y mucho más tribal que el norte" (Nwachukwu et al., 2018).

Para estudiosos africanos como Nwachukwu Egbunike (2018) y el político argelino Imad Mesdoua (2014), esta dicotomía es falsa, ya que los africanos no se definen por una visión colorista, sino por una historia compartida y unos valores que los unen. Pensar que lo "negro" es lo mismo que lo "africano", es producto de una perspectiva colonialista y racista, desde la cual el norte de África no sería lo "suficientemente africana".

En algún momento ha surgido la consideración de que, ser africano, "tal vez sea solo una cuestión de color" (Amrani, 2015). En un artículo para el diario, The Guardian, Iman Amrani escribe: “'Será que ser africano significa ser negro? Y si es así, ¿qué matiz funcionará? ¿Son los sursudaneses con hermosos pigmentos oscuros y ricos, más africanos que sus vecinos del norte de piel más clara?" (Amrani, 2015), se pregunta. Una clasificación basada en la raza, por cierto inexistente (Coppola, 2020), es demasiado reduccionista y no tiene en cuenta la gran diversidad del continente en términos de naciones, culturas y grupos étnicos.

Sin embargo, hay otros puntos en los cuales profundizar para lograr un análisis más completo sobre la diferenciación introducida externamente sobre una África blanca, y una África negra. En 
primer lugar, una serie de acontecimientos que impactaron fuertemente el imaginario colectivo global respecto del norte de África, como una región distinta al resto del continente: las llamadas Primaveras árabes. Entre 2010 y 2012 —años aproximados, si se consideran los casos de Sudán y Alergia (Tisdal, 2019 y Reuters, 2018) - , estos acontecimientos fueron objeto de una fuerte mediatización por parte de occidente.

En tal contexto, el concepto de Medio Oriente que incluía a los países norafricanos, se popularizó fuera del área académica, lo cual produjo o una visión distinta sobre este grupo de países que por primera vez en mucho tiempo, eran "buenos" protagonistas en medios internacionales, en el sentido de comenzar a integrarse al desarrollismo occidental en términos de democracia desde la escena política y social.

No obstante, al poco tiempo comenzaron a escribirse artículos de opinión y notas periodísticas como Quelles retombées des printemps arabes sur l'Afrique subsaharienne? (Verón, 2013); Le printemps arabe et nous (Ngendahayo, 2014) o El impacto de la primavera árabe en África Subsahariana (García-Luengos, 2011), entre otros. Subyace en todos ellos, una perspectiva que supone que los movimientos del norte de África influyen siempre al sur, al África subsahariana; árabes y musulmanes influenciando a los países negros y eliminando la posibilidad de un sur que, a través de sus movimientos sociales y políticos, influya también al norte.

De acuerdo con una perspectiva académica eurocéntrica, la inspiración y empuje hacia la democracia y la liberación del opresor, debe venir del "norte global", y no del sur, confirmando la tesis de Boaventura de Sousa Santos y su Introducción a las epistemologias del sur (2011), sobre la existencia de cierta polaridad dentro de las mismas regiones del norte y sur global. Así, quizá, Medio Oriente y el norte de África representan un norte dentro de un sur global.

Esto lleva a ponerse sobre la mesa la posibilidad del blanqueamiento de países como Libia, Marruecos y Egipto, para poder divulgar más ampliamente el peso del norte, en el sur global. No debe olvidarse que el término de la Primavera árabe, fue acuñado 
por primera vez en la revista estadounidense American Journal of Foreign Policy, donde se señalaba que se trataba de un concepto que ya había sido utilizado para definir algunos movimientos político-sociales similares en Europa, llamados Primaveras de los pueblos (Rihawi, 2018). Posteriormente, se habló del término como un "prestamo histórico", donde la inspiración del movimiento social es Europa, y no África ni Medio Oriente. Un ejemplo más de neocolonialismo, pues no debe olvidarse que la zona se ha convertido en un campo de gran valor geoestratégico debido, sobre todo, a su riqueza energética. Las primaveras en el norte de África podrían haber sido la excusa para mantener el autoritarismo a través de los ejércitos y partidos políticos e instituciones financieras internacionales que se han convertido en los pilares del gobierno mundial - el FMI, el Banco Mundial, la Sociedad Financiera Internacional y la Organización Mundial del Comercio, además del G-8 - , para avanzar y explotar, desde allí, las riquezas del África subsahariana (Zubieta, 2020).

Esto conduce a la reflexión en torno al distanciamiento del norte africano frente al sur subsahariano, tomando en cuenta que muchos norteafricanos se identifican más como árabes o árabe-musulmanes, que como africanos, mientras que los paises al sur del Sahara han sido durante largo tiempo considerados auténticamente africanos (Nwachukwu et al., 2018).

En un artículo titulado “¿Los egipcios son africanos o árabes?”, la periodista egipcia Shahira Amin, comparte una investigación basada en una serie de entrevistas realizadas a personas egipcias de diferentes ámbitos sociales, sobre cómo se ven a ellos mismos:

[...] la mayoría respondió 'soy árabe musulmán... Se encogían de hombros y me miraban perplejos al responder, pues ¿no era un hecho ya sabido que los egipcios son árabes y que Egipto es un país de mayoría musulmana? Algunos entrevistados dijeron ser 'descendientes de los faraones' pero, sorprendentemente, ningunos de los encuestados se consideraba africano (Nwachukwu et al., 2018, \$ 12). 
Por otro lado, Afef Abrougui editora tunecina en Global Voices, comentó:

No me sorprende oír que algunos africanos, particularmente del África subsahariana, cuestionen nuestra 'africanidad', la de los norteafricanos... Hay una broma en Túnez que dice que los tunecinos solo se sienten africanos cuando nuestra selección nacional juega en la Copa Africana de Naciones. No recuerdo haber aprendido en la escuela que Túnez no fuera 'africano', pero la identidad árabe-musulmana sí que era enfatizada, especialmente en la política (Nwachukwu et al., 2018, \$14).

En este sentido, en el preámbulo de la Constitución tunecina de 2014, hay varias referencias a la identidad árabe y musulmana del país, pero solo una a África. "Por supuesto, entiendo por qué los tunecinos se identificarían principalmente como á rabes por el elemento del lenguaje. Sin embargo... África es diversa y deberíamos celebrarlo, en lugar de etiquetar lo que es ser africano" (Nwachukwu et al., 2018, \$ 13).

Joey Ayoub, libanés, también editor de Global Voices, hace una importante reflexión sobre la construcción de las identidades al norte de África frente al sur, y destaca que, a diferencia del panarabismo, el panafricanismo no se convirtió en un ideal con apoyo institucional:

Me parece que la división entre los africanos 'negros' subsaharianos y los 'árabes' del norte de África es el resultado de que el panafricanismo ocupara una ruta histórica diferente, en comparación con el panarabismo. El panarabismo 'ganó', en el sentido de que su narrativa tuvo un apoyo institucional más significativo (la Liga Árabe). También creo que 'ganó' porque la causa palestina coincidió con el periodo del 'antiimperialismo (Nwachukwu et al., 2018, §24).

Estas cuestiones llevan a construir identidades influenciadas por acontecimientos coyunturales distintos, lo que refuerza o modifica las percepciones en torno a las regionalizaciones. 
Por su puesto hay diferencias culturales dentro de un continente tan extenso como África, pero estas no deben reducirse a una cuestión colorista. Una de ellas, por ejemplo, es la religión. A propósito de esto, resulta pertinente retomar un estudio publicado por Pew Research Center (2015). Este consiste en la estimación sobre la composición religiosa de 198 países y territorios de 2010 a 2050. De acuerdo con este estudio, en 2020, en la región del MENA habría 3.6\% de personas cristianas frente a un $93.1 \%$ de población musulmana. En este rubro, países del norte de África como Argelia, Egipto, Marruecos, Sudán, Túnez y el Sahara Occidental - territorio no autónomo bajo supervisión del Comité Especial de Descolonización de la Organización de las Naciones Unidas (UN. Security Council, 2002) - presentan un porcentaje mayor al $90 \%$ en población musulmana. Sin embargo, respecto al África Subsahariana, se estimó un porcentaje del 62\% de población cristiana, frente a un $31.4 \%$ de población musulmana. Así, mientras el islam es actualmente la religión dominante en el norte de África, el cristianismo sigue siendo la religión más profesada en el África subsahariana.

No obstante, las diferencias religiosas no solo se presentan a lo largo de continente africano, también son parte de la misma región del MENA. Un ejemplo al respecto es la población joven de los tunecinos, libios y argelinos, quienes en los últimos años parecen ser significativamente menos religiosos que los del Cercano Oriente. Michael Robbins, director del Barómetro Árabe, explica que (Habtom, 2020), hasta cierto punto, esto puede deberse a los vínculos más fuertes de los países de África del norte, con los países europeos, y menciona que "la fuerte influencia cultural de Francia en Túnez y Argelia, mientras que, en países como Irak o Líbano, la religión sigue siendo fundamental para la propia identidad y es menos probable que se vea afectada por tendencias sociales más amplias" (Habtom, 2020).

En este sentido, mientras que entre los países norafricanos las diferencias étnicas son una característica distintiva, en Oriente Medio lo son las divisiones religiosas. En países como Iraq o Líbano, el sistema político refuerza las identidades religiosas, lo que sirve para au- 
mentar la prominencia de la religión en la vida diaria. Como resultado, es probable que los niveles de religiosidad se mantengan más estables en el Medio Oriente en comparación con el norte de África.

También las desigualdades económicas dentro de los países del MENA son muy grandes. Según datos del Banco Mundial, por ejemplo, para el año 2019 los Emiratos Árabes Unidos mostraban un Producto Interno Bruto (PIB) per cápita de 43.103,3 dólares estadounidenses. El caso de Arabia Saudita fue de 23.139,8 dólares; el de Libia se ubicó en los 7.685,9 dólares y el PIB de Marruecos fue de 3.204,1 dólares (Banco Mundial, 2021).

Por otro lado, la ecuación de identidad en el norte de África, aunque se trate de una cuestión escurridiza y compleja, es posible afirmar que no se reduce a una árabe igual a las de pueblo árabe en Medio oriente: "En el Magreb, todavía hay comunidades que hablan bereber o amazigh y un dialecto llamado darija que tiene muchas expresiones francesas y españolas" (Habtom, 2020). Además, ser árabe no es una alternativa a ser africano o incluso negro en esta región. Los mauritanos y sudaneses se pueden definir como los tres al mismo tiempo.

Así, parece que el rasgo más compartido entre los países del MENA es la presencia del islam, un hecho religioso que es a la vez factor clave del caldo político, social y cultural de la región, así como "experiencia histórica común" (Sestafe, 2019, p. 60), suficientemente distinta al África subsahariana.

En este sentido, para autores como Iman Amrani (2015), es cierto que en muchas ocasiones los gobiernos norteafricanos han intentado distanciarse del "África negra", toda vez que dicho distanciamiento se interpreta en términos de influencia y poder: "después de la independencia, países como Egipto y Argelia miraron hacia el Medio Oriente en busca de un modelo de nación islámica, o hacia Europa, hacia el norte, en busca de alianzas económicas" (Amrani, 2015, §9). Por supuesto, no puede negarse el interés del norte de África en asociarse con Oriente Medio. Arabia Saudita es uno de los cinco principales socios comerciales de Egipto, tanto para las importaciones como para las exportaciones, pero esta relación no es exclusiva. 
70 LA DESIGNACIÓN OCCIDENTAL EN LA CATEgORÍA ANALítica DEL MENA Y SU INFLUENCIA EN LA COMprensión del Continente africano / Beatriz Pineda Ríos

Sin embargo, así como hay diferencias claras entre el norte y el sur del África, también hay lazos esenciales que los unen. En la época actual, uno de ellos es la experiencia de los migrantes. En los suburbios franceses, por ejemplo, los inmigrantes africanos, independientemente si vienen del norte o sur del Sahara, experimentan aislamiento y discriminación. Parece que el interés de clasificar a la población como parte del MENA, separada de un África negra, desaparece en el momento en el que migran a territorios europeos. Una vez ahí, recuperan de inmediato su condición de personas africanas negras.

Una situación que es también es importantes mencionar es el factor de la historia colonial como un elemento compartido a lo largo y ancho del continente africano. Parte de esta historia es la participación de africanos, tanto del norte como del sur, en la Segunda Guerra Mundial, según el mandato de las tropas coloniales francesas e inglesas, también llamadas potencias mundiales. Estos soldados africanos provenían de Argelia, Senegal, Malí, Burkina Faso, Benín, Chad, Guinea, Costa de Marfil, Níger y la República del Congo, Egipto, Nigeria, Sudáfrica y Kenia. Estos hechos forman parte de la memoria colectiva de los países toda África (Sankanu, 2010).

Finalmente, es la poderosa lucha contra el colonialismo europeo, otro elemento que se desprende de la historia colonial y que funge como factor de cohesión en el continente africano, sobre todo, a partir de1960 (Fall, 1991), año conocido como 'el Año de África' debido a los movimientos independistas que resaltaron los crecientes sentimientos panafricanos en el continente (Schwartz, 2010), fueron los novelistas y los poetas, los primeros en hacer la crítica al eurocentrismo, básicamente como afirmación de una cultura africana, o de una personalidad africana (Fall, 1991), lo que posteriormente se fortaleció y se expandió a través de movimientos políticos independentistas.

Fue en este contexto que en 1962 África del Norte se sumó a la lucha en Sudáfrica contra el colonialismo y el apartheid, y que en 1969 la capital de Argelia fue sede del Festival Cultural Panafricano (Azikiwe, 2019). 
La organización que formalmente une al continente africano y cuya concepción encuentra su origen en el panafricanismo, es la Unión Africana. Esta comprende a 55 estados del continente, dividido en cinco regiones geográficas: norte, sur, oeste, este y central. El norte de África está formado por siete países: Argelia, Egipto, Libia, Mauritania, Marruecos, la República Árabe Saharaui Democrática y Túnez (Taboada, 1997).

Los principales actores en la formación de la Organización para la Unidad Africana, que más tarde se convertiría en la Unión Africana, fueron cinco cabezas de estado, a saber: tres de África Subsahariana y dos del norte de África: Kwame Nkrumah, quien después se convertiría en el primer presidente de Ghana, Sekou Toure de Guinea, Leopold Senghor de Senegal, Gamal Abdel Nasser de Egipto y Ahmed Ben Bella de Argelia (Bolívar, 2008).

Todos ellos jugaron un rol igualmente importante en la formación de la Organización para la Unidad Africana (OUA). Por otro lado, Marruecos y Túnez son miembros de las agrupaciones económicas regionales africanas al sur del Sahara (Taboada, 1997), que derivaron de la Unión Africana. Esto permite observar que, en contextos coyunturales para África como un continente extenso, tanto los países del norte como del sur, han actuado conjuntamente, y se han establecido lazos importantes entre ellos. Históricamente las naciones africanas en cuestión han compartido las mismas luchas. En este sentido, Marruecos, Argelia, Túnez, Libia y Egipto no solo comparten un pasado colonial con el resto de África, sino también un continente físico. Si bien la identidad es en gran medida subjetiva, algunas cosas son irrefutables y el hecho de que el norte de África esté en África es una de ellas.

\section{Reflexiones finales}

La historia los términos "Oriente", "Medio Oriente”, el acrónimo MENA, así como un "norte de África” frente al "África subsahariana", muestra que su uso actual en la prensa y en escritos académicos es de origen europeo-occidental, y que no están desvincu- 
72 LA DESIGNACión OCCIDENTAL EN LA CATEgoRía ANALítica DEL MENA Y SU INFLUENCIA EN La Comprensión del Continente africano / Beatriz Pineda Ríos

lados a la hegemonía europea ni al "orientalismo", denunciando por Edward Said.

Tal hegemonía política, social y cultural ejercida sobre territorios muy diversos entre sí, ha llevado a eliminar las complejidades propias de diferentes regiones o países, invisibilizando dinámicas específicas al interior de países como los del norte de África. Centrándose en este último caso, la categoría regional del MENA, ha influido visiblemente en la concepción, tanto interna como externa, de un norte africano desvinculado del resto de África. La construcción de tal concepción se ha visto acompañada por un conocimiento parcial, impreciso y en ocasiones erróneo con respecto, no solo a los países del norte de África, sino también respecto del continente africano en general.

Esto se refleja en las dificultades que la academia orientalista identifica en torno a la definición de realidades sociales del norte de África, al ser estas muy plurales, ya que, basándose en el argumento de que las condiciones históricas y culturales de los países del norte de África, son más afines a las del Medio Oriente, el uso de categorías como el MENA ha tendido reducir su identidad a lo árabe, islámico y oriental, dejando muy de lado la identidad africana que también les constituye.

No se puede negar que a todo esto subyace un valor geoestratégico para Occidente: muestras del interés occidental en dividir el sur global y en particular, el continente africano, hay muchas. Un ejemplo de ello ha sido dividir el continente africano en un norte frente a un África que en más de una ocasión se reduce a la negritud, sin embargo, las diferencias culturales dentro de un continente tan extenso como África, no deben reducirse a una cuestión colorista, la cual se encuentra intrínsecamente vinculada a una perspectiva racista que busca justificar el colonialismo a través del falso argumento de la raza.

Otra forma en la que la categoría del MENA en su construcción orientalista, ha afectado a la visión y comprensión de los territorios que comprende, es el énfasis puesto en el vínculo entre la cultura árabe y el islam a pesar de que tanto en Turquía, Irán y las diferentes sociedades del Sahel y el cuerno de África tuvieron 
lugar experiencias históricas diversas que llevaron a la diferente adaptación y asimilación del islam en sus respectivas sociedades.

A través de todo lo planteado en este texto, es posible identificar un discurso político hegemónico occidental, que no ha dejado de lado categorías que históricamente han generado opresiones no solo en Oriente Medio y el norte de África, sino también a lo largo y ancho del continente a través de procesos muy similares. Actualmente, la categoría del MENA mantiene la base discursiva sobre la cual fue construida hace aproximadamente cincuenta años.

\section{Referencias}

Al-Rahim, M. (2008, 11 de noviembre). Arabism, Africanism, and Self-Identification in the Sudan. The Journal of Modern African Studies, 8(2), 233-249.

Amrani, I. (2015, 11 de septiembre). Pourquoi ne pensons-nous pas à l'Àfrique du Nord comme faisant partie de l'Amerique? The Guardian.https:/www.theguardian.com/commentisfree/2015/ sep/11/algeria-black-africa-north-africa-shared-history

Artehistoria. (2017). África septentrional. ArteHistoria \& Toools, S.L. https://www.artehistoria.com/es/contexto/\%C3\%A1frica-septentrional

Azikiwe, A. (2019, 28 de octubre). Mirando hacia atrás para avanzar: el primer Festival Cultural Panafricano en Argelia, 1969. África Fundación Sur.

Balci, B. (2018). Islam in Central Asia and the Caucasus Since the Fall of the Soviet Union. Oxford University Press.

Banco Mundial, (2021). PIB per cápita (US\$ a precios actuales)-Middle East \& North Africa, https://datos.bancomundial.org/indicador/ny.gdp.pcap.cd?locations=ZQ

Bilgin, P. (2019). Whose 'Middle East?' Geopolitical Inventions and Practices of Security, International Relations, 18(1), 17-33. Bolívar, R. J. (2008). África revolucionaria. Universidad Bolivariana de Venezuela. 
74 LA DESIGNACIÓN OCCIDENTAL EN LA CATEgORÍA ANALítica DEL MENA Y SU INFLUENCIA EN La COMprensión del Continente africano / Beatriz Pineda Ríos

Calduch, R. (2008). Las Relaciones Internacionales culturales entre el islam y occidente. En Cervera Abu Warda (Ed.) Diálogo de Civilizaciones: El Islam y Occidente (pp. 101-131). Instituto de Estudios Islámicos en Madrid.

Child Rights International Network. (2021, 25 de junio). La Liga de los Estados Árabes. https://archive.crin.org/es/biblioteca/publicaciones/la-liga-de-los-estados-arabes.html .

Choueiri, Y. (2000). Arab Nationalism. A history. Blackwell Publishers.

Coppola, L. (2020, 2 de julio). Cómo los huesos acabaron con las razas humanas. The Conversation. Academic Rigor Journalist Fair. https:// theconversation.com/como-los-huesos-acabaron-con-las-razas-humanas-141222.

De la Rosa, A. (2012). Boletín de Información CESEDEN, 323. Montalembert M. y Clément, J. (1983). Disponibilidad de leña en los países en desarrollo. Estudios FAO. http://www.fao. org/3/x5329s/x5329s00.htm\#Contents

Dickson, H. R. P. (1959). The arab of the desert; a glimpse into Badaw in life in Kuwait and Saudi Arabia. George Allen y Unwin.

El Orden Mundial. (2019, 23 de julio). ¿Cuál es la diferencia entre "árabe” y "musulmán"? https://elordenmundial.com/diferencia-arabe-musulman/

Fall, Y. (1991). Historiografía, sociedades y conciencia histórica en África. Estudios de Asia y África. 26(3, 86), 17-37.

Falsa, D. (2006). La situación lingüística del Magreb: lenguas en contacto, diglosia e identidad cultural. Revista española de lingüistica 36, 157-188.

Fierro, M. (2010). The New Cambridge History of Islam, vol. II: The Western Islamic World Eleventh to Eighteenth Centuries. Cambridge University Press.

García-Luengos, J. (2011). El impacto de la primavera árabe en Africa Subsahariana. Grupo de Estudios Africanos. Fundación Alternativas.

Habtom, K.-T. (2020). Is the MENA Region Becoming Less Religious? Arab barometer. Religion and Diplomacy, https:// 
www.arabbarometer.org/2020/04/is-the-mena-region-becoming-less-religious-an-interview-with-michael-robbins/?fbclid=IwAR3urtPZvoXfBJoWg EUBsWqHmkuNOcsM3dImckVtNkkMqaH5F--9dTCM58

Insoll, T. (2003). The Archaeology of Islam in Sub Saharian Africa. Cambridge University Press.

Knut, V. (2010). Sudan, Somalia and the Maghreb to the end of the First World War, The Cambridge History of Islam, vol. V: The Islamic World in the Age of Western Dominance, (pp. 124133). Cambridge University Press.

Lane, E. W. (1863). Arabic English Lexicón. Willams \& Norgate. Levtzion, N. \& Hopkins, J. F. P. (2000). Corpus of early Arabic sources for West African history. Marcus Wiener Publishers.

Levtzion, N. \& Powels, R. (2000). The History of Islam in Africa. Ohio University Press.

Martinez C. J. (1996). Historia del mundo actual. La Vanguardia-Hemeroteca, https://hemeroteca.lavanguardia.com/preview/1945/03/23/pagina4/33088940/pdf.html?search=Liga\%20Arabe

Mesdoua, Imad (2014, 26 de septiembre). Algeria: North Africa's reluctant policeman. African Arguments. https://africanarguments.org/2014/09/algeria-north-africas-reluctant-policeman-by-imad-mesdoua/

Ngendahayo,J. M. (2014, 02 de julio). Le printemps arabe et nous. IWACU. Le voix du Burundi. https://www.iwacu-burundi. org/le-printemps-arabe-et-nous/

Nwachukwu E., Nyamishana, P., Endalkachew, C. \& Rawan, G. (2018, 28 de mayo). How 'African' is Northern Africa? Global Voices, https://globalvoices.org/2018/05/28/how-africanis-northern-africa/

Huntington, S. (2015). El choque de Civilizaciones y la reconfiguración del orden mundial. Paidós.

Pew Research Center \& Public Life. (2015, 2 de abril). The Future of World Religions: Population Growth Projections, 2010-2050. Why Muslims Are Rising Fastest and the Unaffliated Are Shrinking as a Share of the World's Population. 
76 LA DESIGNACión OCCIDENTAL EN LA CATEGORÍA ANALÍTICA DEL MENA Y SU INFLUENCIA EN La COMpRensión del Continente africano / Beatriz Pineda Ríos

https://www.pewforum.org/2015/04/02/religious-projections-2010-2050/

Pew Research Center. Religion and Public Life. (2015, 2 de abril). Religious Composition by Country, 2010-2050. https://www. pewforum.org/2015/04/02/religious-projection-table/2020/ percent/all/

Reuters. (2018, 27 de diciembre). Arab Spring 2.0? Protests after Tunisian journalist calls for revolt, sets himself on fire. Reuters. World News. https://www.rt.com/news/447500-tunisia-journalist-suicide-protest/

Rihawi Pérez, N. (2018). El papel de las redes sociales en la cibercultura: el caso de la "primavera árabe". Tesis doctoral de Periodismo, Universidad Complutense de Madrid.

Roughi, R. (2012). Why are there no Middle Easteners in the Maghrib. En Bonine, M. E. Is There a Middle East? The evolution of a geopolitical concept. (pp. 100-116). Stanford University Press.

Said, E. (2013). Orientalismo. Debate.

Sankanu, B (2010, 22 de noviembre). Cientos de miles de africanos combatieron en la Segunda Guerra Mundial, superando el eurocentrismo de la historia. África Fundación Sur. https://www.africafundacion.org/cientos-de-miles-de-africanos-combatieron-en-la-ii-guerra-mundial-superando-el-eurocentrismo-de-la-historia

Santos, B. S. (2011). Introducción a las Epistemologias del Sur. CLACSO.

Schwartz, S. (2010). Youth and Post-Conflict Reconstruction. United States Institute of Peace.

Sestafe Silvestre, L. (2019). Deconstruyendo el MENA desde una perspectiva histórica y cultural. El concepto de 'Middle East and North Africa' como producto funcional occidental, Relaciones Internacionales, 42, 55-76.

Taboada, H. (1997). Dominaciones y denominaciones: Medio Oriente, países árabes e Islam. Revista Mexicana de Ciencias Politicas y Sociales. 14(167) pp.

Tamayo, J. (2009). Islam. Cultura, religión y politica. Trotta. 
The World Factbook (2021). Somalia. https://www.cia.gov/theworld factbook/static/a84daa7fe6c7ba8e0c9dcb17068655db/ SO-summary.pdf

The World Factbook (2021). Chad. https://www.cia.gov/theworld-factbook/countries/chad/\#people-and-society

Tisdall, S. (2019, 29 de enero). Will corruption, cuts and protest produce a new Arab spring? The Guardian. https://www.theguardian.com/world/2019/jan/26/sudan-egypt-corruptionarab-spring

United Nations. Security Council. (2002, 29 de enero). Letter dated 29 January 2002 from the Under-Secretary-General for Legal Affairs, the Legal Counsel, addressed to the President of the Security Council. https://www.un.org/ga/search/view_ doc.asp?symbol $=S / 2002 / 161$

Véron, J. B. (2013) Quelles retombées des printemps arabes sur l'Afrique subsaharienne ? Introduction thématique. Afrique contemporaine, 1(245), 13-22. https://www.cairn.info/revue-afrique-contemporaine-2013-1-page-13.htm

Wallerstein, I. (1999). El futuro de la civilización capitalista. Icaria. World Population Review. (2021). Mali Population 2021 (Live) https://worldpopulationreview.com/countries/mali-population

Zubieta, J. (2020, 26 de enero). La Primavera Árabe y el África subsahariana: laberintos de poder. Deia, Tribuna abierta. https://www.deia.eus/opinion/tribuna-abierta/2012/03/23/ primavera-arabe-africa-subsahariana-laberintos/207060. html 